\title{
REVISÃO SOBRE TUMORES DESMÓIDE DE PAREDE ABDOMINAL
}

\author{
Vinicius Machado do Couto Soares ${ }^{1}$
}

RESUMO: Tumores desmóides são neoplasias do tecido conjuntivo, caracterizadas por apresentarem crescimento exclusivamente loco-regional, recorrência freqüente e mínimo potencial metastático. Acometem principalmente portadores de polipose adenomatosa familial dos cólons, sendo sua ocorrência isolada extremamente rara. $\mathrm{O}$ objetivo deste trabalho é caracterizar, por meio de uma revisão de literatura, as principais características de pacientes com tumor desmóide e os tratamento utilizados nessa neoplasia. Os resultados mostraram que Tumores desmóides são neoplasias benignas de origem mesenquimal, que se caracterizam por baixo grau histológico, baixo potencial metastático, crescimento loco-regional e taxas consideráveis de recidiva local após ressecção, sendo o trauma tecidual um dos fatores implicados na gênese dessas lesões.

Palavras-chave: Parede Abdominal. Neoplasia. Tumor Desmóide Neoplasias. Fibromatose agressiva.

ABSTRACT: Desmoid tumors are connective tissue neoplasms, characterized by having exclusively locoregional growth, frequent recurrence and minimal metastatic potential. They mainly affect patients with familial adenomatous polyposis of the colon, and their isolated occurrence is extremely rare. The objective of this study is to characterize, through a literature review, the main characteristics of patients with desmoid tumor and the treatments used in this neoplasm. The results showed that Desmoid tumors are benign neoplasms of mesenchymal origin, which are characterized by low histological grade, low metastatic potential, locoregional growth and considerable rates of local recurrence after resection, with tissue trauma being one of the factors involved in the genesis of these lesions.

Keywords: Abdominal wall. neoplasm. Desmoid Tumor Neoplasms. Aggressive fibromatosis.

\section{INTRODUÇÃO}

Os tumores desmóides (TD) são neoplasias raramente descritas, representando 0,03 a $0,13 \%$ dos tumores de partes moles e a incidência é estimada em 2,4 a 4,3 casos novos por 100.00o habitantes por ano (SOUZA et al., 202I). São neoplasias raras, podendo associar-se a polipose adenomatosa familiar (PAF),

\footnotetext{
Médico, residente de Cirurgia Geral da Secretaria Municipal de Saúde de Macaé-RJ. Email:vmiplzon@gmail.com.
} 
especialmente a Síndrome de Gardne, sendo que a etiologia dos tumores desmóides ainda é pouco conhecida (JANES, OJEA \& AZEVEDO, 2016).

Apresentam padrão de crescimento infiltrativo e, menos comumente, originam-se do músculo oblíquo externo e do músculo transversal ou fáscia. São tumores raros que ocorrem em 3,7 casos por milhão de indivíduos a cada ano. Eles foram correlacionados com sexo feminino, PAF e ocasionalmente com trauma abdominal (CASSIDY et al., 2018).

No entanto, o diagnóstico definitivo deve ser estabelecido com análise histopatológica com infiltração celular difusa das estruturas teciduais adjacentes. A resposta imuno-histoquímica para actina pode ser parcialmente positiva e marcadores imuno-histoquímicos de células musculares podem distinguir tumores desmoides de fibrossarcoma (ROCHA et al., 202I).

O objetivo deste trabalho é caracterizar, por meio de uma revisão de literatura, as principais características de pacientes com tumor desmóide e os tratamento utilizados nessa neoplasia.

\section{METODOLOGIA}

Para elaboração deste estudo foi realizada uma revisão da literatura sobre tumores desmóide, foi realizada uma pesquisa através de sites de busca acadêmica: PubMed, Lilacs e Scielo, durante o período de 2015 a 2021. utilizando como termos descritores: câncer, neoplasia abdominal, tumor desmóide, parede abdominal, gravidez, cirurgia, fibromatose agressiva, associando-os em diferentes combinações utilizando a ferramenta Mesh. Foram utilizados os artigos escritos em português e inglês para compor o escopo do trabalho.

\section{CONTEÚdO dA REVISÃO}

Os tumores desmóides são neoplasias benignas raras com forte tendência à invasão local e recorrência. Eles geralmente surgem dos músculos e da aponeurose e podem ser um desafio para o tratamento médico (SANTOS et al., 202I).

Essas lesões também são conhecidas como fibromatoses profundas ou fibromatoses agressivas e têm forte tendência a invadir e recidivar localmente após a 
ressecção, com comportamento biológico intermediário entre tumores fibrosos benignos e fibrossarcomas. Os tumores desmoides podem ser extra-abdominais (ombro, anel pélvico, tórax, pescoço e membros), abdominais, intra-abdominais, múltiplos, familiares múltiplos e associados à PAF ou à síndrome de Gardner (MARTÍ et al., 202I).

Eles representam $0,03 \%$ de todas as neoplasias e $3 \%$ de todos os tumores de tecidos moles. Essas neoplasias são raras, com maior incidência entre 24 e 40 anos, com forte prevalência em mulheres em idade fértil e durante a gestação; eles são incomuns durante a menopausa e isso corrobora a hipótese de crescimento tumoral estimulado por estrogênio. O local mais comum é a parede abdominal anterior, com incidência de $50 \%$ e, neste caso, medem de 5 por $15 \mathrm{~cm}$ de diâmetro (PAREJA et al., 2021).

O diagnóstico diferencial inclui hematoma agudo, fibrossarcoma, linfoma, rabdomiossarcoma, lipossarcoma, leiomiossarcoma, neurofibroma, tumor fibroso benigno e tumor neuroectodérmico primitivo. Os tumores desmoides apresentam três estágios de evolução: no primeiro estágio são mais celulares e possuem menos áreas de colágeno hialinizado (AGUIRRE, 2018). No segundo estágio, há uma quantidade crescente de deposição de colágeno nas áreas centrais e periféricas do tumor. Na terceira etapa há um aumento da composição fibrosa com diminuição da celularidade e do teor de água. Apesar da ausência de potencial metastático, a infiltração e compressão local em locais anatômicos com acesso restrito à ressecção cirúrgica podem levar a óbitos (RUIZ et al., 202I).

A natureza local invasiva e as altas taxas de recorrência desse tipo de lesão obrigam os cirurgiões a manejar com escolhas difíceis e requerem tratamentos complicados. Existem várias possibilidades como ressecção cirúrgica, radioterapia, terapia hormonal (tamoxifeno ou toremifeno) e uso de anti-inflamatórios não esteroidais como indometacina, sulindac ou celecoxib (GARCIA-ORTEGA et al., 2020).

A radioterapia tem sido utilizada predominantemente para o tratamento de tumores desmoides extra-abdominais e tem resultado na melhora do controle local por meio da redução das taxas de recorrência local. A irradiação com feixe externo ou 
a braquiterapia podem ser utilizadas isoladamente, principalmente em pacientes com lesões irressecáveis, mesmo que estejam correlacionadas com altas taxas de insucesso. Eles também podem ser usados como novas terapias adjuvantes após ressecção cirúrgica incompleta (HOWARD \& POLLOCK, 2016).

Existem vários estudos e relatos de casos que descrevem abordagens cirúrgicas para ressecção de tumores desmoides quando presentes na parede abdominal, mas a melhor estratégia cirúrgica é controversa e depende do histórico do paciente e da preferência do cirurgião (MINATTA, SPECTERMAN \& WRIGHT, 2018)

\section{${ }_{4}$ CONSIDERAÇÕES FINAIS}

Os tumores desmoides são neoplasias raras que surgem em muitos espaços anatômicos e exigem decisões desafiadoras. Uma ressecção radical com margens livres continua sendo o principal determinante do resultado. A estratégia de tratamento ideal para tumores desmoides ainda permanece incerta. Uma abordagem multidisciplinar é sempre a melhor estratégia para estabelecer o tratamento correto.

A estratégia de tratamento ideal para tumores desmoides ainda permanece incerta. A cirurgia é o tratamento primário e uma ressecção radical com margens livres continua sendo o principal determinante do resultado. Abordagens não cirúrgicas podem ser úteis para terapia adjuvante em pacientes com lesões irressecáveis. Mais estudos são necessários para estabelecer a melhor estratégia, mas a abordagem deve ser sempre multidisciplinar como aconselha a maioria dos estudos tidos como referência nesse trabalho.

\section{REFERÊNCIAS}

SOUZA, B. G. et al. Tumor Desmoide de Parede Abdominal: Relato de Caso. Journal of Coloproctology, v. 4I, n. S oI, p. A290, 2021.

JANNES, C Z.; OJEA, A R.; AZEVEDO, M A. CISTO REACIONAL DE PAREDE ABDOMINAL APÓS HERNIOPLASTIA VENTRAL SIMULANDO TUMOR DESMÓIDE. 2016. 
CASSIDY, Michael R. et al. Associação da intensidade do sinal T2 da RM com a progressão do tumor desmoide durante a observação ativa: um estudo de coorte retrospectivo. Anais de cirurgia, 2018.

ROCHA, Kaio Danilo Leite da Silvaet al. Desmoid tumor of the abdominal wall: Case report. Amadeus International Multidisciplinary Journal, v. 6, n. II, p. 34-42, 2021.

SANTOS, Daniel Britto et al. Tumor Desmóide: Relato de Caso. Brazilian Journal of Development, v. 7, n. II, p. I01782-101792, 2021.

MARTÍ, Beatriz Pallarés et al. Tumor desmoide cervical gigante: relato de caso. Brazilian Journal of Otorhinolaryngology, v. 87, p. 634-637, 2021.

PAREJA, Helen Brambila Jorge et al. Tumor desmoide abdomino pélvico: um relato de caso. Brazilian Journal of Development, v. 7, n. 7, p. 74025-74028, 2021.

AGUIRRE, Gabriela Katherine Zurita. Tumor desmoide. Revista Médica-Científica CAMbios HECAM, v. i7, n. I, p. 76-8o pp., 2018.

RUIZ, Nuria López et al. Tumor desmoide de mama: descripción de un caso. Revista de Senología y Patología Mamaria, 202I.

GARCIA-ORTEGA, Dorian Yarih et al. Desmoid-type fibromatosis. Cancers, v. I2, n. 7, p. 1851, 2020.

HOWARD, J. Harrison; POLLOCK, Raphael E. Fibromatose desmoide intraabdominal e da parede abdominal. Oncologia e terapia , v. 4, n. I, pág. 57-72, 2016.

MINATTA, Nicolás; SPECTERMAN, Sergio; WRIGHT, Fernando. Tumor desmoide abdominal. Oncol. clín, p. 35-37, 2018. 